\title{
INCLUSÃO ESCOLAR NO ENSINO MÉDIO: DESAFIOS DA PRÁTICA DOCENTE
}

\section{SCHOOL INCLUSION IN SECONDARY SCHOOL: CHALLENGES OF THE TEACHING PRACTICE}

\author{
Patrícia Mara Almeida GARCIA ${ }^{\mathrm{i}}$ \\ Rosimeire Ferreira DINIZ ${ }^{\text {ii }}$ \\ Morgana de Fátima Agostini MARTINS ${ }^{\text {iii }}$
}

RESUMO: Este artigo apresenta os dados de uma pesquisa que desenvolvemos como parte de uma disciplina do Programa de Pós-Graduação em Educação Escolar da FCL/CAr da Unesp, que se propôs a analisar o trabalho docente no contexto da inclusão escolar em todos os níveis de ensino. Realizamos uma pesquisa com professores do Ensino Médio, de uma escola do interior de Minas Gerais, que atendia alunos públicoalvo da educação especial - PAEE. O objetivo foi observar e analisar como tem se dado o processo de inclusão nesta unidade escolar, quais os desafios enfrentados e os subsídios oferecidos pela escola. Desenvolvemos uma pesquisa de abordagem qualitativa, utilizamos como procedimento metodológico o Estudo de Caso e como instrumentos de pesquisa usamos um questionário, que foi aplicado a 5 professores, realizamos observações com registro em diário de campo para caracterizar a escola em relação a sua estrutura física e para compreensão dos processos pedagógicos, analisamos o Projeto Político Pedagógico e a dinâmica de estruturação da escola. Os resultados mostram, entre outros, que a inclusão de alunos PAEE no Ensino Médio ainda é muito frágil, que os professores não se sentem preparados e, portanto, não realizam adaptações considerando as diferenças, que o PPP não é elaborado de forma coletiva e participativa e que se faz necessário um engajamento de toda a equipe escolar na busca das alterações necessárias.

PALAVRAS-CHA̧VE: Educação especial. Inclusão escolar. Ensino médio.

ABSTRACT: This article presents data from a survey developed as part of a course of the Graduate Program in School Education FCL / CAr Unesp, which aimed to analyze the teaching work in the context of school enrollment at all educational levels. We conducted a survey of high school teachers from a school in Minas Gerais, which met target group of special education students - EEAP. The objective was to observe and analyze how has given the process of inclusion in this school unit, which faced challenges and subsidies offered by the school. Developed a qualitative research, used as a methodological procedure the case study and as research tools use a questionnaire, which was applied to five teachers, conducted observations record in field diary to characterize the school in relation to its physical structure and to understand the pedagogical processes, we analyze the pedagogical Political Project and the dynamics of school organization. The results show, among others, the inclusion of EEAP students in high school is still very fragile, that teachers do not feel prepared and therefore do not make adjustments considering the differences that the PPP is not developed in a collective and participatory manner and that it is necessary an engagement of all school staff in finding the necessary changes.

KEYWORDS: Special education. School inclusion. High school. 


\section{Introdução}

A constituição Federal garante a todos os indivíduos o direito à educação de qualidade no ensino regular em instituições públicas de ensino.

Nesse contexto é fato que a sociedade precisa passar por algumas mudanças no sentido de entendimento do sentido da letra da lei, uma vez que historicamente esta não tem sido a política vigente, ou seja, não escolarizamos todos os cidadãos nos mesmos espaços. Parte dessas mudanças está relacionada a atitude para com a diferença. Educacionalmente falando, construímos ao longo do tempo um modelo de escola homogeneizador, que categoriza os indivíduos e os divide a partir de critérios estabelecidos socialmente, desconsiderando as particularidades e o potencial formador das mesmas. Embora as características humanas de diferença sejam infindáveis, neste trabalho de pesquisa vamos nos ater a uma análise de um grupo específico, chamados nas políticas públicas atuais de PAEE - Público-Alvo da Educação Especial, que compreende pessoas com deficiências (intelectual, física, auditiva e visual) ou múltiplas (em que as características de deficiências se apresentam combinadas), pessoas com transtornos globais de desenvolvimento e pessoas com altas habilidades/superdotação.

Sabemos que o meio escolar é um pilar fundamental para o desenvolvimento do indivíduo em geral e, quando falamos de indivíduos PAEE, o papel da escola se agiganta, uma vez que a mesma terá que construir estratégias diferenciadas das comumente utilizadas para garantir o desenvolvimento e a aprendizagem desse grupo com características distintas. Dentre vários aspectos que merecem atenção neste processo de redefinição da escola, a prática pedagógica se apresenta como indispensável. Analisar a prática pedagógica implica necessariamente em discutir a identidade do professor, tendo em vista que todo processo educativo escolar está diretamente relacionado à sua atuação, embora dependa de uma estrutura macro e micro.

Compreende-se que a atuação pedagógica na escola está diretamente relacionada ao bom aprendizado dos seus alunos. Porém, uma série de fatores converge para a obtenção desses resultados, e é através dos Indicadores da Qualidade na Educação que se avalia as condições necessárias para que esse objetivo seja alcançado. Acredita-se que não tem sido valorizado o potencial humano na maioria das escolas da rede pública de educação, e isso acontece, entre outras razões, por questões de conformismo do sistema e consequentemente do docente que na maioria das vezes não consegue fazer 
uma ligação entre sua formação e ação prática, atua em um segmento desarticulado, e muitas vezes constrói sua identidade profissional a partir de uma visão descaracterizada e desvalorizada da profissão.

A qualidade do trabalho do professor está vinculada a uma série de condições: quantidade de alunos em cada turma que atende, horário de trabalho, tempo disponível para preparação das aulas, apoio de profissional preparado para o acompanhamento contribuindo para sua prática educativa, qualidade dos recursos didáticos existentes na escola, reuniões de estudo, entre outros. Esse vínculo de qualidade na escola se entrelaça às questões de identidade e formação dos profissionais que atuam nessa Instituição e que, assim, são agentes ativos no processo para tornar a escola pública o espaço adequado à aquisição de conhecimentos pelos alunos.

Questões relacionadas à identidade e formação do professor tem ocupado lugar de destaque, por questões políticas, teóricas e práticas. No caso da teorização e prática pedagógica, tem-se realçado a necessidade de se discutir a identidade do docente, tendo em vista que o fim do processo educativo escolar está diretamente relacionado à sua atuação.

Nessa concepção, as abordagens das políticas educacionais oferecidas devem estar direcionadas à formação docente que atue na direção de preparar sujeitos críticos, autônomos, criativos, humanos, capazes de atuar de forma dinâmica e positiva. Neste contexto educacional, a figura do professor é imprescindível como articulador entre o conhecimento e o aluno. Sobre a formação do professor, a Lei de Diretrizes e Bases 9.394/96, Capítulo IX, p. 237, diz: “A educação do docente é o primeiro caminho a ser percorrido para a solução de muitos problemas, a começar pela consideração de que o professor é um homem do saber e um artista, e não um tecnocrata".

Nesta perspectiva, a formação inicial e em serviço é indispensável ao professor e essencial à sua atuação com o aluno. Ensinando, o professor se depara com ideias dos alunos que se diferenciam das suas, troca experiências, reflete sobre sua atuação e sobre formas de ensinar, e assim ao ensinar também aprende e produz conhecimento. Para tanto, a formação de professores do ensino regular precisa ser repensada com vistas a atender aos princípios inclusivos. Para torná-los capazes de desenvolver uma educação inclusiva, cursos de formação de professores do ensino regular devem estar inteiramente voltados para práticas que acompanhem a evolução das ciências da educação e que não excluam nenhum aluno. "A formação deve ser um processo de construção do 
conhecimento transformador de situações da vida cotidiana tanto dos professores quanto de toda a instituição onde trabalham" (PRADA, 1997, p.147).

O professor por ser um agente formador contribui para que as mudanças e avanços necessários a partir de sua ação na escola aconteçam na sociedade. Seu trabalho deve ser motivo de constante alegria, por ser ele um profissional com possibilidades de, junto com o aluno, transformar-se e transformar o outro. Justifica-se, portanto, repensar a instituição escola, com vistas a ultrapassar seus muros, rever seu projeto políticopedagógico, trabalhar em rede, numa visão multidisciplinar, organizar estratégias diversificadas que beneficiem o aluno no seu contexto, não referente apenas ao PAEE mas a todo o público escolar.

\section{A inclusão no Brasil: conceitos e legislação}

O termo inclusão significa que toda sociedade precisa repensar seus conceitos para reconhecer as potencialidades de cada indivíduo. A escola para ser inclusiva deve estabelecer um espaço democrático que promova a participação de todos respeitando suas peculiaridades.

O Estatuto da Criança e do Adolescente recomenda em seu Art.15: “A criança e o adolescente têm direito à liberdade ao respeito e à dignidade como seres humanos em processo de desenvolvimento". A criança e o adolescente têm direito à educação, visando o pleno desenvolvimento de sua pessoa, assegurando-lhes igualdade de condições para o acesso e permanência na escola.

A Declaração de Salamanca (1994) ressalta que:

(...) O princípio da inclusão consiste no reconhecimento de necessidade de se caminhar rumo à escola para todos, um lugar que inclua todos os alunos celebre as diferenças, apoie a aprendizagem e responda às necessidades individuais (UNESCO,1994,p.03).

E ainda, conforme a Lei de Diretrizes e Bases da Educação Brasileira LDB, 9394/96 p.22:

Entende-se por educação especial, para os efeitos dessa lei, a modalidade de educação escolar, oferecida na escola regular de ensino para educandos com necessidades especiais. Haverá quando necessário, serviços especializados na escola regular, para atender às peculiaridades da clientela de educação especial. O atendimento educacional será feito em classes, ou serviços especializados sempre 
que, em função das condições específicas dos alunos não for possível a sua integração nas classes comuns do ensino regular. A oferta de educação especial dever educacional do Estado, tem início na faixa etária de 0 a seis anos, durante a educação infantil.

Podemos tomar como referencial a lei de Diretrizes e Bases da Educação Brasileira (LDB 9394/96), visto que nela está o direito de acesso, nas instituições escolares, dos alunos com necessidades educacionais especiais, com início na educação infantil, em rede regular de ensino, além do ensino fundamental, médio e superior.

Anterior a LDB, a Constituição da República Federativa do Brasil (1988) já dispunha que é dever do Estado garantir atendimento educacional especializado às pessoas com deficiência, preferencialmente na rede regular de ensino. A Constituição da República Federativa Brasileira é a Lei maior do país e defende com clareza a responsabilidade do Estado para com a educação das pessoas com algum tipo de deficiência.

Considerando que a diferença é inerente ao ser humano, e reconhecendo a diversidade como algo natural, em que cada ser pode usar de seus direitos coletivos na sociedade, um novo conceito surge, denominado Inclusão. "Este é o termo que se encontrou para definir uma sociedade que considera todos os seus membros como cidadãos legítimos" (MANTOAN, 1997, p.41.).

A escola em geral, coordenação, professores e demais funcionários, devem assumir o compromisso de tornar a escola inclusiva, acreditando que as mudanças são possíveis desde que haja uma transformação nos atuais modelos de ensino, conforme declara Mantoan:

\footnotetext{
Acredito que ao incluir crianças com necessidades especiais na escola regular, estamos exigindo desta instituição novos posicionamentos diante dos processos de ensino e de aprendizagem, à luz de concepções e práticas pedagógicas mais evoluídas: (MANTOAN, 1997, p.120).
}

Nesse sentido, a inclusão de alunos PAEE nas escolas tem se tornado um grande desafio para a maioria dos professores, além do que nem sempre as escolas têm demonstrado interesse em mudar seus posicionamentos para receber estes alunos. Assim, um grande caminho ainda necessita ser percorrido para que estas práticas pedagógicas realmente aconteçam. A inclusão de todos se dá quando o professor elabora um planejamento educacional que possibilite o desenvolvimento e a 
aprendizagem de todos os alunos de acordo com as características de cada um e considere a necessidade existente dentro da sala de aula.

Para que a inclusão seja efetuada, é necessário que o trabalho seja executado em todo o âmbito escolar, não somente dentro de sala de aula, e também é necessária uma maturidade, um olhar diferente, e aceitação de todo o grupo escolar para que compreendam o aluno e suas dificuldades.

Deve se promover uma formação permanente de todos os envolvidos no processo de aprendizagem, institucional, familiar e diálogo com toda comunidade. Os pais devem ser orientados devendo participar de todo processo, pois senão todo o esforço dos professores e envolvidos estará sendo praticamente em vão.

A inclusão é, em última instância, um processo de fornecer aos alunos com deficiência uma educação com o máximo de qualidade e de eficácia, no sentido da satisfação das suas necessidades individuais.

\section{A inclusão no Ensino Médio:}

Conforme Quenn (2012), de acordo com dados que fazem parte do Resumo Técnico do Censo Escolar 2011, o número de alunos com necessidades educacionais especiais (NEE) em classes comuns do Ensino Médio cresceu significativamente, triplicando entre 2007 e 2011. À primeira vista, esses dados nos chamam a atenção por seu aspecto positivo, mas um olhar mais aprofundado mostra que ainda há necessidade de obter avanços, isso porque a quantidade de matrículas - e a qualidade do acesso por trás desses números- ainda está muito aquém do ideal. Enquanto no Ensino Fundamental alunos com NEE representam 1,4\% do total; no Ensino Médio, apesar do crescimento, representam são apenas $0,4 \%$. A disparidade sinaliza que um número considerável de pessoas com alguma deficiência deixa a escola sem chegar à última etapa da Educação Básica.

Entre os fatores que contribuem para essa desigualdade destaca-se a própria estrutura do Ensino Médio - que em muitas instituições ainda está associado a uma formação medida apenas pela produtividade intelectual ou profissional. Como consequência, falta espaço nos currículos para uma preocupação devida com a inclusão. Somam-se a isso os problemas já conhecidos de infraestrutura escolar voltada ao atendimento a esses alunos, comuns em todas as etapas da Educação Básica. 
No que diz respeito à temática das aprendizagens, Zabala (1998) salienta que elas dependem das características singulares de cada um dos aprendizes e a forma como se aprende e o ritmo de aprendizagem variam segundo as capacidades, interesses e motivações de cada indivíduo. Com esta ótica pedagógica é possível observar a atenção à diversidade e identificar necessidades individuais dos alunos. Cabe ao professor fazer este percurso e buscar estratégias de trabalho que permitam responder adequadamente às necessidades individuais de todos os alunos. Temos que considerar também a flexibilização do currículo e dos processos avaliativos. Sobre este aspecto, Zardo (2012) destaca que a viabilidade da inclusão de estudantes com deficiência no sistema de ensino somente será possível se discutidos e transformados os processos de avaliação da aprendizagem. Esta transformação contempla mudanças de concepção sobre o processo de avaliação da aprendizagem e da postura do professorado em face da sua atuação profissional (ZARDO, 2012: 291). Desta maneira, mostra-se necessário romper com estruturas sistêmicas que vão desde o investimento na área até a revisão da estrutura do Ensino Médio para a valorização da diversidade no processo de aprendizagem, considerando que as escolas devem adotar currículos flexíveis, possibilitando as respectivas modificações e adequações em atendimento aos alunos com necessidades educacionais especiais. Tais mudanças devem estar em consenso com os princípios definidos no PPP- Projeto Político Pedagógico da própria escola, colaborando para excelente efetivação de um ensino de qualidade para todos os alunos.

\section{Método}

Considerando os aspectos brevemente desenvolvidos acima, desenvolvemos como parte de uma disciplina do Programa de Pós-Graduação em Educação Escolar da FCLAr da Unesp, que se propôs a analisar o trabalho docente no contexto da inclusão escolar em todos os níveis de ensino, uma pesquisa com professores do Ensino Médio, de uma escola do interior de Minas Gerais, que atendia alunos PAEE. O objetivo foi observar e analisar como tem se dado o processo de inclusão nesta unidade escolar, quais os desafios enfrentados e os subsídios oferecidos pela escola. Desenvolvemos uma pesquisa de abordagem qualitativa, utilizamos como procedimento metodológico o Estudo de Caso e como instrumentos de pesquisa usamos um questionário, que foi aplicado a 5 professores, realizamos observações com registro em diário de campo para 
caracterizar a escola em relação a sua estrutura física e para compreensão dos processos pedagógicos, analisamos o Projeto Político Pedagógico e a dinâmica de estruturação da escola.

O questionário foi aplicado aos professores que se encaixavam no perfil de amostra da pesquisa. Foram no total cinco professores que lecionam no ensino médio e alguns desses também no fundamental. O questionário utilizado nesta pesquisa continha sete perguntas objetivas, tendo como ponto principal saber se os professores têm noções básicas de como trabalhar com o aluno que apresenta algum tipo de necessidade especial, identificar se estão sendo orientados para desenvolver seu trabalho com todos os alunos, questionar o que os professores entendem por inclusão educacional, buscar junto a esses profissionais informações sobre o PPP da escola, se consta proposta de uma educação inclusiva, como são elaborados e qual a contribuição dos profissionais na construção desse plano.

\section{Resultados e discussão}

\section{Caracterização da Escola}

A Escola pesquisada está situada no interior de Minas Gerais, teve sua implantação executada pelo próprio Estado no ano de 1974 com instalações físicas parcialmente adequadas ao ensino. Na escola são matriculados em média 1600 alunos por ano. O ensino é dividido em Fundamental, séries finais, Ensino Médio, Normal Pós Médio e Educação de Jovens e Adultos, nos três turnos de funcionamento, sendo que o Ensino Médio funciona no período matutino e noturno. O seu quadro de professores é composto por cinquenta e nove profissionais, sendo que quarenta e dois atuam no Ensino Médio, onde cem por cento tem Ensino Superior completo e aproximadamente vinte por cento está cursando e/ou terminaram Mestrado, mas ambos não participam de nenhuma formação continuada referente à inclusão escolar. Destaca-se na observação realizada a necessidade de maior dimensionamento da parte administrativa da escola. $\mathrm{Na}$ parte física seria necessário observar as necessidades de adaptação em relação aos banheiros, para que atenda as necessidades de todos os alunos da escola, inclusive alunos usuários de cadeiras de rodas, de acordo com as normas da ABNT 9050. A escola não possui Sala de Recursos Multifuncionais para atender alunos PAEE. 
Em relação ao corpo discente, observamos que a clientela da instituição pesquisada é composta por alunos de classe social média baixa, que residem em bairros adjacentes à escola. Um dado observado é a superlotação da maioria das salas de aula, que é considerado um dos "fatores que contribuem para um baixo rendimento escolar" e consequentemente refletem na qualidade da escola.

De acordo com as observações realizadas, o planejamento escolar é realizado no início do ano letivo e tem a participação especificamente dos professores e supervisores. Os tipos de avaliações desenvolvidas são: diagnóstica e formativa, contemplando toda a produção e participação dos alunos em um processo dinâmico, contínuo, aplicadas igualmente a todos os alunos sem adaptações para atender necessidades individualizadas. Para alunos que apresentam alguma dificuldade acentuada e/ou deficiência, é proposto pelos professores sentarem em duplas para que todos consigam realizar as atividades em sala de aula, até mesmo as avaliações.

Os materiais utilizados pelos professores para a ministração das aulas variam, sendo livros didáticos, cadernos, quadro de giz, cartazes, data show, reforçando que nenhum material é adaptado para atender as necessidades de todos os alunos.

Foi observado que existem vários alunos que apresentam necessidades especiais “incluídos" nas diversas salas comuns. De todos os alunos observados notamos que apenas 2 têm acesso a um material diversificado, que consiste em material ampliado e mesa adaptada devido à baixa visão.

Outro fator a destacar é a organização estrutural da escola que necessita de uma sala de recursos multifuncionais devido a grande demanda de alunos PAEE e um ambiente sinalizado e adaptado. Adaptações estas como rampas de acesso, banheiros adaptados com corrimãos, portas mais largas, mesas para usuários de cadeiras de rodas, material pedagógico adaptado de acordo com as necessidades de todos alunos.

\section{Perfil dos professores e alunos PAEE da escola pesquisada:}

Quadro 1. Perfil dos professores elaborado a partir dos dados dos questionários. 


\begin{tabular}{|l|c|c|}
\hline \multicolumn{1}{|c|}{ PROFESSORES } & TOTAL & ENSINO MÉDIO \\
\hline Formação superior & 59 & 42 \\
\hline Com mestrado e ou cursando & 20 & 20 \\
\hline Formação continuada em educação especial e áreas afins & 5 & 5 \\
\hline Outros (curso de Libras e Braille) & 3 & 3 \\
\hline
\end{tabular}

Fonte: Elaboração dos autores.

Quadro 2. Tipo de deficiência dos alunos elaborado a partir dos dados dos questionários.

\begin{tabular}{|cc|}
\hline DEFICIÊNCIA & TOTAL de ALUNOS \\
Intelectual & 12 \\
Física & 2 \\
Visual/Baixa visão & 2 \\
Auditiva/Surdez & 2 \\
Múltipla & 1 \\
\hline
\end{tabular}

Fonte: Elaboração dos autores.

\section{Análise das respostas às perguntas do questionário}

Os questionários foram respondidos por 5 professores que tinham em suas turmas alunos PAEE e que se dispuseram a participar da pesquisa. Apresentaremos as respostas dispostas em quadros com o intuito de melhor analisar as congruências e incongruências.

Quadro 3. Questão 1 do questionário aplicado aos professores.

\begin{tabular}{|l|l|}
\hline Questão 1 & $\begin{array}{l}\text { O que é, para você, a inclusão do aluno que apresenta necessidades educacionais } \\
\text { especiais? }\end{array}$ \\
\hline Professor 1 & Inclusão é aceitar todos alunos na escola. \\
\hline Professor 2 & É recebê-lo com o mesmo carinho, oportunizando os mesmos direitos e deveres. \\
\hline Professor 3 & $\begin{array}{l}\text { Deveria ser feita a inclusão intelectual com profissionais especializados. Atualmente a } \\
\text { inclusão é somente fictícia, pois só coloca o aluno na sala mas não dentro do dialogo, } \\
\text { também o coloca como o diferente o que faz com que ele seja alvo de bulling. }\end{array}$ \\
\hline Professor 4 & É uma oportunidade de socialização desse aluno. \\
\hline Professor 5 & Não sei dizer. \\
\hline
\end{tabular}

Fonte: Elaboração dos autores.

Essas respostas expressam uma dificuldade por parte desses professores no sentido de entendimento do real significado do conceito de inclusão, que vai desde uma 
afirmação literal "não sei dizer", passando por uma ideia de socialização e aceitação com foco no indivíduo, desconsiderando assim o princípio básico do conceito, que consiste em uma reorganização escolar capaz de oferecer condições equânimes de ensino e aprendizagem para todos os alunos.

Quadro 4. Questão 2 do questionário aplicado aos professores.

\begin{tabular}{|l|l|}
\hline Questão 2 & $\begin{array}{l}\text { Você tem algum aluno na sua sala, ou na sua escola que apresenta necessidades } \\
\text { educacionais especiais? Se tiver, como você tem trabalhado? }\end{array}$ \\
\hline Entrevista 1 & Sim, trabalho igualmente com todos alunos. \\
\hline Entrevista 2 & $\begin{array}{l}\text { Tenho. Trabalho normalmente como um todo, até mesmo para não trazer } \\
\text { constrangimento. }\end{array}$ \\
\hline Entrevista 3 & $\begin{array}{l}\text { Na medida do possível o professor tenta mas é difícil ocupar varias funções ao mesmo } \\
\text { tempo e também sem preparo. }\end{array}$ \\
\hline Entrevista 4 & Sim. Procuro conhecer cada aluno em particular para agir da melhor maneira. \\
\hline Entrevista 5 & Tenho não faço diferenciação. \\
\hline
\end{tabular}

Fonte: Elaboração dos autores.

As respostas para a questão 2 reforçam o desconhecimento em relação ao papel da escola para com todos os alunos, uma vez que o reconhecimento das diferenças e o oferecimento de respostas compatíveis com as especificidades dos alunos é um dos pilares do modelo inclusivo. Ao referirem que trabalham igualmente, que não fazem diferenciação, estão negando o caráter equânime fundamental da escola. Um dos professores se refere à falta de preparo, o que é real, no entanto, a dimensão atitudinal, que deve explicitar o entendimento de que a diversidade faz parte da escola e que ela precisa ser observada e valorizada, ainda não faz parte do discurso dos professores.

Quadro 5. Questão 3 do questionário aplicado aos professores.

\begin{tabular}{|l|l|}
\hline Questão 3 & $\begin{array}{l}\text { Na Escola que você atua é feito Projeto Político Pedagógico (PPP)? Como ele é } \\
\text { realizado? }\end{array}$ \\
\hline Entrevista 1 & Sim, no início do ano letivo todos professores participam. \\
\hline Entrevista $\mathbf{2}$ & Sim. Reunindo pessoal de cada área para trocas de ideias e ai se constrói o PPP. \\
\hline Entrevista 3 & Sim. Através de projetos que envolvam os alunos e a comunidade. \\
\hline Entrevista 4 & Sim. É realizado com discussões para sua elaboração. \\
\hline Entrevista 5 & Sim. No início ano letivo. \\
\hline
\end{tabular}

Fonte: Elaboração dos autores. 
Em relação a questão 3, todos os professores responderam que a escola elabora o Projeto Político Pedagógico e quatro dos cinco respondentes disseram que é com a participação, discussão e envolvimento, inclusive com menção aos alunos e comunidade.

Quadro 6. Questão 4 do questionário aplicado aos professores.

\begin{tabular}{|l|l|}
\hline Questão 4 & No PPP é inserida a Educação Especial? Se sim, de que forma? \\
\hline Entrevista 1 & Acho que não. \\
\hline Entrevista 2 & Sim, aceitando-os como todos os direitos e deveres do cidadão. \\
\hline Entrevista 3 & Não sei. \\
\hline Entrevista 4 & Não. \\
\hline Entrevista 5 & Creio que não. \\
\hline
\end{tabular}

Fonte: Elaboração dos autores.

As respostas da questão 4, no entanto, que perguntou se a Educação Especial faz parte do Projeto Político Pedagógico, parecem desmentir a participação coletiva afirmada na questão anterior, uma vez que três professores afirmam não saber, ou seja, se realmente participassem da elaboração do referido projeto, que deveria traduzir os anseios da escola, saberiam se esse tema, a Educação Especial, foi ou não contemplado. Por outro lado, temos duas respostas contraditórias, uma afirmando que sim e outra que não. Vale lembrar que os professores são da mesma escola, portanto, estão falando do mesmo Projeto Político Pedagógico. Esta contradição sugere, no mínimo, que este tema não ocupa lugar de destaque nas discussões desta escola, o que nos permite inferir que o respeito e valorização das características individuais, e o esforço para atender as necessidades delas decorrentes está minimizado.

Quadro 7. Questão 5 do questionário aplicado aos professores.

\begin{tabular}{|l|l|}
\hline Questão 5 & $\begin{array}{l}\text { Na escola que atua é oferecido suporte para lidar com os casos de inclusão? Se sim, } \\
\text { como é realizado? }\end{array}$ \\
\hline Entrevista 1 & Não temos nenhum suporte nem apoio. \\
\hline Entrevista 2 & Não. \\
\hline Entrevista 3 & Também não tenho essa informação. \\
\hline Entrevista 4 & Não. \\
\hline Entrevista 5 & Não é oferecido. \\
\hline
\end{tabular}

Fonte: Elaboração dos autores. 
Em relação ao suporte para a realização de um trabalho inclusivo, as respostas evidenciam que ainda não se constituem como realidade nesta escola. $\mathrm{O}$ atendimento educacional especializado, além de ser um direito constitucional aos alunos com deficiência, é um recurso imprescindível para a participação de todos em igualdade de oportunidades. A título de exemplo, se considerarmos alunos com deficiências sensoriais, como auditivas e visuais, sem a utilização de linguagens e códigos diferenciados, como a Libras e o Braile, é impossível uma participação plena no processo de ensino aprendizagem. Embora esses exemplos confirmem nitidamente a premissa apresentada, pelas suas especificidades diferenciadas, o princípio é o mesmo para todo e qualquer aluno que em virtude de características próprias necessitem de auxílios diferenciados.

Quadro 8. Questão 6 do questionário aplicado aos professores.

\begin{tabular}{|l|l|}
\hline Questão 6 & $\begin{array}{l}\text { Você acredita no processo de inclusão dos alunos com necessidades educacionais } \\
\text { especiais? O que você acha que pode melhorar, ou o que está faltando? }\end{array}$ \\
\hline Entrevista 1 & Sim, os professores necessitam de mais orientação e cursos na área. \\
\hline Entrevista 2 & $\begin{array}{l}\text { Sim, acredito. Deveria ter um orientador ou auxiliar para nos ajudar, porque sendo salas } \\
\text { numerosas fica muito a desejar. }\end{array}$ \\
\hline Entrevista 3 & $\begin{array}{l}\text { É uma via de mão dupla o aluno especial pega características do "normal” e este pega } \\
\text { atributos ao especial. }\end{array}$ \\
\hline Entrevista 4 & $\begin{array}{l}\text { O processo de inclusão precisa de políticas especiais direcionados para esse aluno, como } \\
\text { formação de professor. }\end{array}$ \\
\hline Entrevista 5 & Não acredito. \\
\hline
\end{tabular}

Fonte: Elaboração dos autores.

Em relação às suas crenças pessoais sobre o processo de inclusão, as respostas demonstram em sua maioria - quatro dos cinco professores - que assumimos um discurso politicamente correto no sentido de que todos têm os mesmos direitos, porém;, esse discurso é permeado por concepções de que esse processo é externo, ou seja, acredito desde que tenha formação para os professores, acredito desde que tenha um auxiliar, desde que tenha menos alunos nas salas, desde que tenham políticas especiais, ou seja, algo ou alguém deve fazer alguma coisa para a inclusão acontecer. O "eu professor", profissional responsável pelo processo de ensino aprendizagem dos alunos que me são designados a cada ano, me isento de fazer com que esse processo se concretize. Não podemos deixar de analisar a resposta de um professor que diz não acreditar. É possível que sua resposta esteja baseada na realidade que conhece, que 
como vimos é ambígua e, portanto, demonstra que se estamos chamando de inclusão escolar esse modelo presente nas escolas brasileiras, em que alunos com deficiência são matriculados nas escolas e isso resume o processo de inclusão, a sua descrença se justifica.

A crença no processo de inclusão escolar deveria ser um princípio norteador de todo profissional da educação que, cidadão de uma sociedade democrática que deveria ser justa, o defenderia para além de conjunturas políticas ou estruturais, como imprescindível para sustentação do ideal democrático que tanto almejamos.

Quadro 9. Questão 7 do questionário aplicado aos professores.

\begin{tabular}{|l|l|}
\hline Questão 7 & $\begin{array}{l}\text { Nas Salas que atua tem aluno especial? Como você desenvolve seu trabalho com esse } \\
\text { aluno? É feito algum tipo de adaptação ou plano especial? }\end{array}$ \\
\hline Entrevista 1 & Sim. Sempre peço que sente em dupla para que o colega possa auxiliar. \\
\hline Entrevista 2 & $\begin{array}{l}\text { Sim. Desenvolvo o trabalho normalmente o adaptando junto a esse aluno, como: } \\
\text { trabalhar em grupo ou dupla e atendendo-o mais frequentemente. }\end{array}$ \\
\hline Entrevista 3 & Existe aluno especial e o método pedagógico que eu uso é a paciência somente. \\
\hline Entrevista 4 & $\begin{array}{l}\text { Sim. Meu trabalho é desenvolvido para dar atenção especial para esses alunos. Não há } \\
\text { adaptações e nem plano especial. }\end{array}$ \\
\hline Entrevista 5 & Sim, igualmente a todos alunos. \\
\hline
\end{tabular}

Fonte: Elaboração dos autores.

Todos os professores que participaram desta pesquisa tinham alunos com deficiência em suas turmas, porém nenhum deles refere qualquer tipo de adaptação especifica considerando a deficiência como fator de diferenciação. A inclusão de alunos com deficiência na escola comum não elimina suas necessidades decorrentes da deficiência e sua inclusão deve significar que a escola as reconhece e implementa ações estruturais e pedagógicas para atendê-las. As respostas a esta questão demonstram, mais uma vez, o despreparo da escola e dos professores que lidam com esta realidade ignorando-a, como se o simples auxílio de um colega, não preparado para essa função, ou agir com paciência significassem uma escola de qualidade para todos.

\section{Conclusões}

O objetivo desse trabalho era analisar como tem se dado o processo de inclusão no Ensino Médio considerando as demandas atuais da Educação Especial. Através dessa 
pesquisa observamos que além dos professores não serem bem preparados, falta informação e compreensão de toda equipe escolar no que se refere à educação inclusiva.

Com base nos dados acima apresentados, podemos inferir que a ideia de inclusão para esses professores é apenas a oportunidade de socialização. Importante ressaltar que do ponto de vista deles a escola teria que contratar profissionais especializados para melhor atender os alunos com necessidades especiais porque os mesmos não se sentem preparados nem responsáveis por desenvolver um trabalho diferenciado com esses alunos. Afirmam que a formação continuada precisa ser revista para embasar-se mais na Educação Especial, que hoje está acontecendo de forma rudimentar. Outra questão é o Projeto Politico Pedagógico, há uma distorção nas falas dos professores que não sabem realmente se está contemplado na sua elaboração a Educação Inclusiva, e qual a proposta em relação ao público-alvo da Educação Especial. No Projeto Político Pedagógico por nós analisado, consta que a escola se compromete com a Educação Inclusiva aceitando todos os alunos, que na prática são apenas matriculados, falta trabalho pedagógico específico, recursos didáticos que visem atender às necessidades dos alunos público-alvo da Educação Especial.

Mostra-se necessário romper com estruturas sistêmicas que vão desde o investimento até a revisão da estrutura do Ensino Médio para a valorização da diversidade no processo de aprendizagem. Vale ressaltar que há necessidade de uma modificação da educação para a conquista da cidadania, envolvendo também uma mudança dos professores quanto à sua prática pedagógica. Essa é uma tarefa política cuja finalidade é fazer dos profissionais da educação pessoas mais engajadas na transformação da sociedade, implementando projetos educacionais do sentido excludente ao sentido inclusivo.

Sustenta-se que a Educação Inclusiva é um desafio que nos obriga a repensar a escola em geral, incluindo sua cultura, sua política, suas práticas pedagógicas e o corpo docente. Dessa forma estará atendendo todos, inclusive aqueles atualmente marcados pelo ciclo de exclusão e do fracasso escolar. Ainda nesta mesma linha de considerações podemos concluir que a Educação Inclusiva no Brasil ainda está começando, todavia, esperamos que o contínuo aprimoramento de projetos nesse sentido, formação em serviço de professores e demais agentes educacionais e conscientização de toda a sociedade, contribua para as mudanças necessárias.

Para finalizar, cabe ressaltar que a inclusão não é uma utopia, nem apenas uma expressão linguística e física de um processo histórico e que não tem fim, é 
responsabilidade de todos, devendo ser entendida dentro do enfoque dinâmico, processual e sistêmico que procuramos levantar nesta pesquisa.

\section{Referências}

BRASIL. Ministério da Educação e Cultura. Adaptações Curriculares de Pequeno Porte. Brasília, 2000.

Estatuto da criança e do adolescente: Lei federal $\mathbf{n}^{\mathbf{0}} \mathbf{8 0 6 9}$, de 13 de julho de 1990. Rio de Janeiro: Imprensa Oficial, 2002.

Ministério da Educação e Cultura. Secretaria da Educação Especial. Diretrizes Nacionais para a Educação Especial na Educação Básica. Brasília, 2001. 83p.

Lei 9.394/96, de 20 de dezembro de 1996. Estabelece as diretrizes e bases da educação nacional. Diário Oficial da República Federativa do Brasil. Brasília, 1996. Disponível em <http://www.planalto.gov.br/ccivil_03/Leis/L9394.htm>. Acesso em 14 set. 2015.

DEMO, P. Desafios modernos da educação. 4. ed. Petrópolis: Vozes, 1993.272p.

GOULART, O. M. T. O desafio da universalização do ensino médio. Brasília: Instituto Nacional de Estudos e Pesquisas Educacionais Anísio Teixeira, 2006. 20p. (Série Documental. Textos para Discussão).

MANTOAN, M. T. E. A Integração de pessoas com deficiência: Contribuições para uma reflexão sobre o tema. São Paulo: Memnon, 1997.

NÓVOA, A (Coord.). Os professores e sua formação. Lisboa: Dom Quixote, 1992.

PAQUAY, L.; PERRENOUD, P.; ALTET, M. (Orgs.). Formando professores profissionais: Quais estratégias? Quais competências? 2. ed. Porto Alegre: Artmed, 2001.

PIMENTA, S. G. Saberes pedagógicos e atividade docente. 8. Ed. São Paulo: Cortez, 2005.

PRADA, L. E. A. Formação Participativa de Docentes em Serviço. São Paulo: Cabral Universitária, 1997.

QUEEN, M. Inclusão no Ensino Médio ainda é para poucos. Revista Nova Escola (digital), São Paulo. ed. 253p. jun/julh. 2012. Disponível em: $<$ http://revistaescola.abril.com.br/politicas-publicas/inclusao-ensino-medio-aindapoucos-688994.shtml>. Acesso em: 15 ago. 2015. 
UNESCO. Declaração de Salamanca. Sobre Princípios, Políticas e Práticas na Área das Necessidades Educativas Especiais. Salamanca, 1994.

ZABALA, A. A prática educativa: como ensinar. Porto Alegre: Artmed, 1998.224p.

ZARDO, S. P. Direito à educação: a inclusão de alunos com deficiência no ensino médio e a organização dos sistemas de ensino. 2012. 378 f. Tese (Doutorado em Educação) - Faculdade de Educação da Universidade de Brasília, Brasília, 2012. Disponível em <http://repositorio.unb.br/bitstream/10482/12582/1/2012_SinaraPollomZardo.pdf>. Acesso em: 15 set. 2015.

\section{Como referenciar este artigo}

GARCIA, Patrícia Mara Almeida.; DINIZ, Rosimeire Ferreira.; MARTINS, Morgana de Fátima Agostini. Inclusão escolar no ensino médio: desafios da prática docente. Revista Ibero-Americana de Estudos em Educação, v. 11, n. esp. 2, p.1000-1016, 2016. Disponível em: <https://dx.doi.org/10.21723/riaee.v11.esp2.p1000-1016>. EISSN: 1982-5587.

\section{Sobre os autores}

\footnotetext{
i Aluna Especial. UNESP - Universidade Estadual Paulista. Faculdade de Ciências e Letras - Pósgraduação em Educação Escolar. Araraquara - SP - Brasil. 14800-901 - patriciamara2007@ hotmail.com ii Aluna Especial. UNESP - Universidade Estadual Paulista. Faculdade de Ciências e Letras - Pósgraduação em Educação Escolar. Araraquara - $\mathrm{SP}$ - Brasil. 14800-901 rosimeireferreiradiniz@gmail.com

iii UFGD - Universidade Federal da Grande Dourados. Faculdade de Educação - Pós-graduação em Educação. Dourados - MS - Brasil. 7984-970 - morganamartins@ufgd.edu.br
} 